\title{
Exigências nutricionais de metionina+cistina para poedeiras semipesadas do início de produção até o pico de postura ${ }^{1}$
}

\author{
José Jordão Filho ${ }^{2}$, José Humberto Vilar da Silva ${ }^{3}$, Edson Lindolfo da Silva ${ }^{4}$, Marcelo Luis \\ Gomes Ribeiro ${ }^{2,5}$, Terezinha Domiciano Dantas Martins ${ }^{5}$, Carlos Bôa-Viagem Rabello ${ }^{6}$
}

\author{
${ }^{1}$ Parte da dissertação de Mestrado do primeiro autor apresentada ao PPGZ/CCA/UFPB, Areia - PB \\ 2 Doutorado Integrado em Zootecnia, PDIZ/CCA/UFPB, Areia - PB. \\ ${ }^{3}$ DAP/CFT/UFPB, Bananeiras, PB e PPGZ - CCA/UFPB, Areia, PB. Bolsista PQ do CNPq. \\ ${ }^{4}$ Doutorado em Zootecnia da UFLA, Lavras - MG. Bolsista do CNPq. \\ ${ }^{5} D A P / C F T / U F P B$, Bananeiras - $P B$. \\ 6 UFRPE.
}

RESUMO - O experimento foi realizado com a finalidade de determinar as exigências nutricionais de metionina + cistina $(\mathrm{M}+\mathrm{C})$ de poedeiras semipesadas. Foram utilizadas 360 aves distribuídas em delineamento inteiramente casualizado, com cinco tratamentos e 12 repetições de seis aves. As rações experimentais com 17,2\% PB (isoprotéicas) e $2.800 \mathrm{kcal} \mathrm{EM} / \mathrm{kg}$ (isocalóricas) foram formuladas à base de milho e farelo de soja para atender às exigências de todos os nutrientes, exceto $\mathrm{M}+\mathrm{C}$, sendo suplementadas com DL-metionina (99\%) em substituição ao amido de milho para proporcionar cinco níveis $(0,61 ; 0,68$; 0,$75 ; 0,82$ e $0,89 \%$ ) de $\mathrm{M}+\mathrm{C}$ total. As características de desempenho foram avaliadas no período de 20 a 44 semanas de idade das aves. Os níveis de $\mathrm{M}+\mathrm{C}$ afetaram o desempenho das aves, com efeito quadrático sobre o peso dos ovos, a massa de ovos e a conversão por massa de ovos. As estimativas encontradas foram de 0,$73 ; 0,69$ e $0,69 \%$ de $\mathrm{M}+\mathrm{C}$ total ou 0,$66 ; 0,63$ e $0,63 \%$ de $\mathrm{M}+\mathrm{C}$ digestível respectivamente. Portanto, recomenda-se 0,70 e $0,64 \%$, ou consumo de 762 e $697 \mathrm{mg}$, respectivamente, de $\mathrm{M}+\mathrm{C}$ total e digestível/ave/dia para poedeiras semipesadas do início de produção até o pico de postura.

Palavras-chave: aminoácido, desempenho, nutrição

\section{Methionine + cystine requirements of semi-heavy laying hens from the starter to peak of egg production}

\begin{abstract}
A trial was carried out to determine the nutritional requeriments of methionine + cystine $(\mathrm{M}+\mathrm{C})$. A total of 360 laying hens was allotted to a completely randomized design with five treatments and 12 replicates of six birds. The corn-soybean meal based diets were formulated to be isonitrogenous $(17.2 \% \mathrm{CP})$ and isoenergy $(2,800 \mathrm{kcal} \mathrm{ME} / \mathrm{kg})$ to meet the bird requeriment in all nutrients, except for $\mathrm{M}+\mathrm{C}$, that was supplemented with DL-methionine (99\%) in replacement with corn starch. The following total $\mathrm{M}+\mathrm{C}$ levels were obtained: $0.61,0.68,0.75,0.82$, and $0.89 \%$. All variables were evaluated from 20 to 44 weeks old. Egg weight, egg mass and egg mass:feed ratio were all affected quadratically by the M+C levels. The estimates obtained were: $0.73,0.69$, and $0.69 \%$ of total lysine and $0.66,0.63$, and $0.63 \%$ of digestible $\mathrm{M}+\mathrm{C}$, respectively. Therefore, it is recommended levels of 0.70 and $0.64 \%$ or intake of 762 and $697 \mathrm{mg}$ total and digestible $\mathrm{M}+\mathrm{C} / \mathrm{bird} / \mathrm{day}$, respectively, for semi-heavy laying hens from the starter to peak of egg production.
\end{abstract}

Key Words: amino acid, performance, nutrition

\section{Introdução}

A tendência mundial de elevação dos preços das fontes protéicas (Silva et al., 2000) e energéticas das rações avícolas tem motivado os nutricionistas à formulação de rações para máximo retorno econômico. Com o fornecimento de aminoácidos industriais, é possível melhorar a qualidade e reduzir o conteúdo protéico das rações, diminuir o catabolismo e a excreção de nitrogênio das aves e controlar a poluição ambiental, sem elevar os custos de produção.
Os aminoácidos essenciais são exigidos pelo organismo das poedeiras para atender três necessidades básicas: mantença, formação de tecidos corporais e deposição de proteína para o ovo. Considerando que na produção comercial de ovos deve-se priorizar a otimização da conversão da proteína dietética em proteína do ovo, erros na concentração dos aminoácidos nas rações podem comprometer o desempenho produtivo e econômico das aves.

A formulação de rações com milho e farelo de soja não atende completamente às exigências em metionina e lisina, tornando necessária a utilização de fontes industriais 
destes aminoácidos para suprir estas deficiências (Togashi et al., 2002), aumentando a eficiência de utilização da proteína dietética.

A metionina é o primeiro aminoácido limitante, seguido da lisina, em rações para aves. A metionina na forma de S-adenosilmetionina é o mais importante doador de grupos metil no organismo, sendo exigida para a biosíntese de substâncias envolvidas no crescimento, como cisteína, creatina, carnitina, poliaminas, epinefrina, colina e melatonina (Baker et al., 1996).

Em condições práticas, rações deficientes em metionina reduzem a produção e o peso dos ovos e aumentam a deposição de gordura no fígado de poedeiras. Porém, vários fatores influenciam as exigências de metionina+cistina, como o teor de proteína da ração, a linhagem, o ambiente térmico e o teor energético, assim como a presença de fatores antinutricionais e o processamento da matériaprima utilizada na ração. Calderon \& Jensen (1990) verificaram que o aumento da suplementação de DL-metionina, associado à elevação da concentração de proteína da ração, melhorou a produção de ovos, o peso, a massa de ovos, o consumo e a conversão alimentar.

Nos últimos anos, foram introduzidas no mercado linhagens comerciais de poedeiras com melhor capacidade para conversão dos nutrientes da ração. Por isso, é importante o conhecimento das exigências nutricionais dessas aves para obtenção de máximo desempenho a custo mínimo.

Apesar de as linhagens semipesadas constituírem mais de $25 \%$ do plantel brasileiro (Silva et al., 2005), as mesmas foram escassamente estudadas em experimentos de exigências nutricionais. Portanto, objetivou-se com este trabalho estimar as exigências em metionina + cistina do início ao pico de produção de ovos em poedeiras semipesadas.

\section{Material e Métodos}

O experimento foi conduzido no Núcleo de Pesquisa em Aves do Centro de Formação de Tecnólogos (CFT), Campus III, da Universidade Federal da Paraíba (UFPB), situado no município de Bananeiras, na microrregião do Brejo. Foram utilizadas 360 poedeiras semipesadas da linhagem Hisex Brown com 20 semanas de idade e 1,64 $\pm 0,05 \mathrm{~kg}$ de peso vivo. A seleção das aves foi realizada com base no peso vivo e na produção de ovos, avaliada durante 14 dias antes do início das coletas de dados. As aves foram submetidas a um programa de iluminação de 17 horas/dia (luz natural + luz artificial).

Foram alojadas duas aves por gaiola convencional $(25 \times 45 \times 40 \mathrm{~cm})$, em galpão experimental com cobertura de telhas de barro em duas águas, pé-direito de 1,8 m de altura, duas fileiras de gaiolas sobrepostas e um corredor de $1 \mathrm{~m} \mathrm{de}$ largura entre as fileiras. O galpão possuía área correspondente a $75,6 \mathrm{~m}^{2}(2,8 \times 27 \mathrm{~m})$ e orientação leste-oeste.

O experimento foi desenvolvido entre 20 e 44 semanas de idade das aves, estendendo-se do início até o pico de postura. As temperaturas e umidades relativas do ar míni-

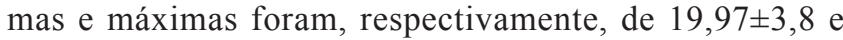
$29,34 \pm 5,9^{\circ} \mathrm{C}$ e $60,92 \pm 6,3$ e $95,22 \pm 8,9 \%$.

Foi estudado um total de cinco tratamentos, constituídos pelos níveis de metionina +cistina $(\mathrm{M}+\mathrm{C})$ total, de 0,61 ; 0,$68 ; 0,75 ; 0,82$ e $0,89 \%$, e 12 repetições de seis aves. As aves foram alimentadas com uma ração basal (17,2\% PB, 2.800 $\mathrm{kcal} \mathrm{EM} / \mathrm{kg})$ deficiente em $\mathrm{M}+\mathrm{C}(0,61 \%)$ suplementada com cinco níveis de DL-metionina com 99\% de atividade de metionina $(0,020 ; 0,091 ; 0,162 ; 0,233$ e $0,304 \%)$ em substituição ao amido de milho. A ração basal (Tabela 1) foi formulada de acordo com as sugestões de Rostagno et al. (2000).

Os teores protéicos e energéticos dos ingredientes e os valores totais e digestíveis de $\mathrm{M}+\mathrm{C}$, do milho, do farelo de soja e do glúten de milho, tomados como base para a estimativa da $\mathrm{M}+\mathrm{C}$ total e digestível nas rações, são apresentados na Tabela 2.

A água foi fornecida à vontade, mas a oferta de ração farelada foi equalizada em $110 \mathrm{~g} / \mathrm{ave} / \mathrm{dia}$ ou consumo estimado de $308 \mathrm{kcal} / \mathrm{ave} / \mathrm{dia}$, suficiente para atender às necessidades de mantença e produção segundo o modelo de predição descrito por Rostagno et al. (2000), considerando $1,6 \mathrm{~kg}$ como peso vivo médio das aves, $1 \mathrm{~g}$ como ganho de peso diário e $55 \mathrm{~g}$ de massa de ovos produzida.

As características de desempenho produtivo estudadas foram: consumo de ração (g/a/d), peso vivo final (g), ganho de peso $(\mathrm{g})$, produção de ovos $(\% / \mathrm{a} / \mathrm{d})$, peso $(\mathrm{g})$ e massa de ovos $(\mathrm{g} / \mathrm{a} / \mathrm{d})$, conversão alimentar por massa $(\mathrm{kg} /$ $\mathrm{kg})$ e por dúzia de ovos $(\mathrm{kg} / \mathrm{dz})$, consumo de $\mathrm{M}+\mathrm{C}(\mathrm{mg} / \mathrm{a} / \mathrm{d})$ e consumo de $\mathrm{M}+\mathrm{C}$ por massa de ovos ( $\mathrm{mg} / \mathrm{g}$ ), pesos $(\mathrm{g})$ e porcentagens de gema, clara e casca, além da gravidade específica dos ovos $\left(\mathrm{g} / \mathrm{cm}^{3}\right)$. Os pesos de gema, clara e casca foram obtidos a partir do valor médio dos últimos três dias de cada período experimental, enquanto as porcentagens de gema, clara e casca foram estimadas em relação ao peso dos ovos. A gravidade específica (GE) foi determinada pelo método recomendado por Hempe et al. (1988), considerando-se a relação do peso do ovo no ar e o peso do ovo após imersão completa em água destilada, multiplicada pela densidade da água a $23^{\circ} \mathrm{C}(0,99754)$, segundo a expressão:

$$
\mathrm{GE}\left(\mathrm{g} / \mathrm{cm}^{3}\right)=\frac{\text { peso do ovo no } \operatorname{ar}(\mathrm{g})}{\text { peso do ovo submerso em } \mathrm{H}_{2} \mathrm{O} \text { destilada }} \times 0,99754
$$


Tabela 1- Composição alimentar e nutricional da ração basal ${ }^{1}$ Table 1 - Ingredient and chemical compositions of the basal diet

\begin{tabular}{lc}
\hline $\begin{array}{l}\text { Ingrediente } \\
\text { Ingredient }\end{array}$ & $\begin{array}{c}\text { Ração basal } \\
\text { Basal diet }\end{array}$ \\
\hline Milho (Corn) & 61,86 \\
Farelo de soja (Soybean meal) & 19,96 \\
Glúten de milho (Corn gluten) & 4,20 \\
Calcário (Limestone) & 9,94 \\
Fosfato bicálcico (Dicalcium phosphate) & 1,51 \\
Amido (Starch) & 0,78 \\
DL-metionina (DL-methionine) & 0,02 \\
L-lisina·HCl (L-lysine HCl) & 0,27 \\
Cloreto de colina (70\%) (C. chloride) & 0,20 \\
Óleo vegetal (Vegetable oil) & 0,45 \\
Sal comum (Salt) & 0,55 \\
Premix vitamínico ${ }^{2}$ (Vitamin mix) & 0,20 \\
Premix mineral ${ }^{3}$ (Mineral mix) & 0,05 \\
Inerte ${ }^{4}$ (Inert) & 0,01 \\
Total & 100,00 \\
\hline
\end{tabular}

Composição química

Chemical composition

\begin{tabular}{|c|c|}
\hline Proteína bruta (\%) (Crude protein) & 17,20 \\
\hline Energia metabolizável $(\mathrm{kcal} / \mathrm{kg})(M E)$ & 2.800 \\
\hline Gordura $(\%)($ Fat $)$ & 2,99 \\
\hline Cálcio (\%) (Calcium) & 4,28 \\
\hline Fósforo disponível (\%) & 0,37 \\
\hline \multicolumn{2}{|l|}{ Available phosphorus } \\
\hline Metionina+cistina (\%) $\mathrm{T}^{5} \quad($ Met + Cys $)$ & 0,61 \\
\hline Metionina+cistina $(\%) \mathrm{D}^{5} \quad($ Met + Cys $)$ & 0,54 \\
\hline Metionina (Methionine) (\%) $\mathrm{T}$ & 0,31 \\
\hline Metionina (Methionine) (\%) D & 0,29 \\
\hline Lisina (Lysine) $(\%) \mathrm{T}$ & 0,97 \\
\hline Lisina (Lysine) (\%) D & 0,84 \\
\hline Arginina (Arginine) $(\%) \mathrm{T}$ & 0,91 \\
\hline Arginina (Arginine) $(\%) \mathrm{D}$ & 0,85 \\
\hline Fenilalanina+Tirosina $(\%)(P h e+T y r)$ & 1,52 \\
\hline Isoleucina (Isoleucine) $(\%) \mathrm{T}$ & 0,60 \\
\hline Treonina (Threonine) (\%) $\mathrm{T}$ & 0,65 \\
\hline Treonina (Threonine) (\%) D & 0,48 \\
\hline Triptofano $\mathrm{T}$ (Tryptophan) (\%) & 0,18 \\
\hline Triptofano D (Tryptophan) (\%) & 0,15 \\
\hline Valina (Valine) $(\%) \mathrm{T}$ & 1,35 \\
\hline Valina (Valine) (\%) D & 1,24 \\
\hline Leucina (Leucine) $(\%) \mathrm{T}$ & 0,67 \\
\hline Leucina (Leucine) (\%) D & 0,59 \\
\hline Sódio (Sodium) (\%) & 0,25 \\
\hline Cloro (Chloride) (\%) & 0,36 \\
\hline Potássio (Potassium) (\%) & 0,56 \\
\hline \multicolumn{2}{|l|}{ Balanço eletrolítico $(\mathrm{Na}+\mathrm{K}-\mathrm{Cl})(\mathrm{mEg} / \mathrm{kg})$} \\
\hline Acid base balance & 151,34 \\
\hline
\end{tabular}

${ }_{1}^{1}$ Recomendações de Rostagno etal. (2000) (According to Rostagno etal., 2000 tables). 2 Composição por kg do produto (Composition/kg of product): Vit. A $10.000 .000 \mathrm{UI}$; Vit. $D_{3} 2.500 .000$ Ul; Vit. E 6.000 Ul; Vit. K 1.600 mg; Vit. $B_{12} 11.000$ mg; Niacina (niacin) 25.000 mg; Ácido fólico (folic acid) 400 mg; Ácido pantotênico (pantothenic acid) $10.000 \mathrm{mg}$; Selênio (selenium) $300 \mathrm{mg}$; Antioxidante (antioxidant) $30 \mathrm{~g}$; Veículo (carrier) q.s.p.

${ }^{3}$ Composição por kg do produto (Composition $/ \mathrm{kg}$ of product): $\mathrm{Mg}-150.000 \mathrm{mg}$; Zn - 100.000 mg; Fe - 100.000 mg; Cu - 16.000 mg; I -1.500 mg; Veículo (carrier) q.s.p.

4 Inerte: areia lavada (washed sand)

${ }^{5} \mathrm{~T}$ = aminoácido total (total amino acid); $\mathrm{D}$ = aminoácido digestível (digestible amino acid).

O delineamento experimental utilizado foi o inteiramente casualizado e as análises estatísticas foram realizadas por meio do programa SAEG - Sistema de Análise Estatística e Genética, desenvolvido pela Universidade Federal de Viçosa
Tabela 2 - Composições protéica e energética dos ingredientes e valores totais e digestíveis de metionina + cistina do milho, farelo de soja e glúten de milho

Table 2 - Energy and crude protein compositions of the ingredients and digestible and total values of methionine + cystine of corn, soybean meal and corn gluten

\begin{tabular}{|c|c|c|c|c|}
\hline \multirow[t]{2}{*}{$\begin{array}{l}\text { Ingrediente } \\
\text { Ingredient }\end{array}$} & \multirow{2}{*}{$\begin{array}{c}\text { Proteína } \\
\text { bruta (\%) } \\
\text { Crude protein }\end{array}$} & $\begin{array}{l}\text { EMAn } \\
(\mathrm{kcal} / \mathrm{kg})\end{array}$ & \multirow[t]{2}{*}{$\begin{array}{c}\text { Total } \\
\text { Total }\end{array}$} & \multirow[t]{2}{*}{$\begin{array}{c}\text { Digestível }^{3} \\
\text { Digestible }\end{array}$} \\
\hline & & $M E$ & & \\
\hline $\begin{array}{l}\text { Milho }{ }^{1} \\
\text { Corn }\end{array}$ & 8,57 & 3.371 & 0,37 & 0,325 \\
\hline $\begin{array}{l}\text { Farelo de soja }{ }^{1} \\
\text { Soybean meal }\end{array}$ & 45,54 & 2.266 & 1,27 & 1,120 \\
\hline $\begin{array}{l}\text { Glúten de milho }{ }^{1}(60 \%) \\
\text { Corn gluten }\end{array}$ & 59,85 & 3.775 & 2,50 & 2,300 \\
\hline $\begin{array}{l}\text { Amido } \\
\text { Starch }\end{array}$ & 0,55 & 3.625 & - & - \\
\hline $\begin{array}{l}\text { DL-metionina } \\
\text { DL-methionine }\end{array}$ & 58,70 & 3.680 & - & - \\
\hline $\begin{array}{l}\text { L-Lisina } \cdot \mathrm{HCl}^{2} \quad(78,4 \%) \\
\text { L-Lysine } \mathrm{HCl}\end{array}$ & 119,80 & 4.600 & - & - \\
\hline $\begin{array}{l}\text { Óleo vegetal }{ }^{1} \\
\text { Vegetable oil }\end{array}$ & 0,0 & 8.790 & - & - \\
\hline
\end{tabular}

1 Segundo Rostagno et al. (2000) (According to Rostagno et al., 2000 tables).

2 Segundo NRC (1994) (According to NRC, 1994 tables).

3 Valores de met+cis descritos por Rostagno et al. (2000) (Met+cys values according to Rostagno et al., 2000 tables).

- UFV (1993). As estimativas das exigências de metionina + cistina foram estabelecidas por meio do modelo de regressão polinomial, considerando o valor do $\mathrm{R}^{2} \mathrm{e}$ a resposta biológica das aves.

\section{Resultados e Discussão}

As características de desempenho, consumo de ração, peso vivo final, ganho de peso, produção de ovos, peso de ovos, massa de ovos e conversão por massa e por dúzia de ovos das poedeiras, de acordo com os níveis de metionina + cistina das rações experimentais, são apresentadas na Tabela 3.

Observou-se redução linear do consumo de ração $(\mathrm{P} \leq 0,01)$ com o aumento dos níveis de $\mathrm{M}+\mathrm{C}$ da ração(Figura 1), indicando que o excesso de aminoácidos sulfurosos reduz o consumo das aves, como descrito por Goulart (1997), em que o excesso de aminoácidos na corrente sangüínea provoca a redução no consumo voluntário das aves. O resultado encontrado neste trabalho diverge do obtido por Togashi et al. (2002), que observaram estimativa de $0,57 \%$ de $\mathrm{M}+\mathrm{C}$ total em poedeiras de 51 semanas de idade alimentadas com dietas à base de milho, farelo de soja e levedura, provavelmente porque as aves estavam em idade avançada, apresentando, portanto, exigência específica, ou por causa das diferenças no teor protéico da ração utilizada pelos autores $(13 \% \mathrm{~PB})$. 


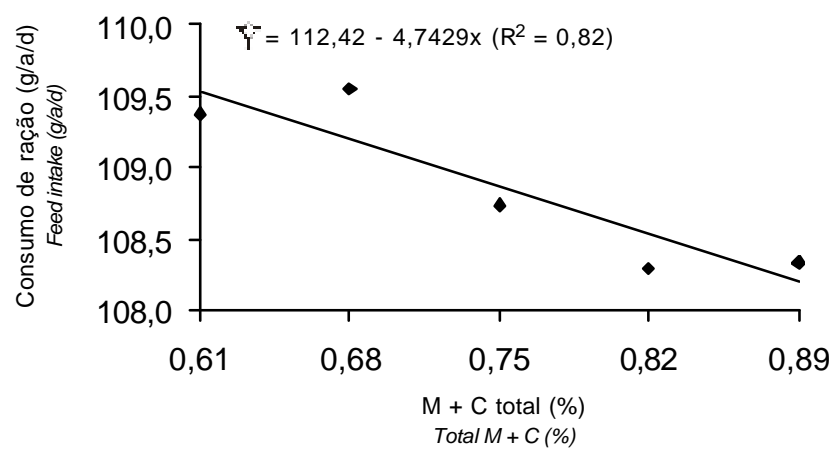

Figura 1 - Efeitos dos níveis de $M+C$ total sobre o consumo de ração.

Figure 1 - Feed intake according to the dietary $M+C$ total levels.

As aves possuem a habilidade de reduzir a ingestão de alimento para compensar o excesso de aminoácidos da ração, fato confirmado neste estudo. Segundo Leung \& Rogers (1971) e Gietzen (1993), existem evidências de que a alteração dos níveis dos aminoácidos limitantes em relação ao total dos aminoácidos na ração provoca o desbalanço, detectado no córtex pré-periforme anterior do cérebro, seguido por mudanças comportamentais, como redução do consumo de ração. Desta forma, a diminuição observada no consumo é uma estratégia para situações de alta ingestão de misturas desbalanceadas, que podem causar lesão patológica (Sidrauskej \& Baba, 1960). Esta redução do consumo é normalmente percebida 2 a 3 dias do início da alimentação das aves com uma dieta desbalanceada (Park \& Austic, 1998). De acordo com Macari et al. (1994), o excesso de ingestão de aminoácidos pelas aves também pode desencadear efeito aminostático, reduzindo o consumo das aves.
O peso vivo das aves foi influenciado de forma quadrática ( $\mathrm{P} \leq 0,05)$, com valor máximo no nível de $0,77 \%$ de $\mathrm{M}+\mathrm{C}$ total, enquanto o ganho de peso cresceu linearmente $(\mathrm{P} \leq 0,05)$ com o aumento dos níveis de $\mathrm{M}+\mathrm{C}$ da ração. Ao contrário, Togashi et al. (2002) não observaram efeito dos níveis de $\mathrm{M}+\mathrm{C}$ da ração sobre o ganho de peso em poedeiras. Novak et al. (2004), no entanto, observaram diferença no ganho de peso ao testarem a adição de 959 ou $860 \mathrm{mg}$ de lisina total/ave/dia na ração.

A produção de ovos diminuiu linearmente com o aumento do nível de $\mathrm{M}+\mathrm{C}$ total da ração (Figura 2) e a diminuição do consumo alimentar causada pelo excesso de $\mathrm{M}+\mathrm{C}$ da ração foi, talvez, o principal fator deste declínio, possivelmente em virtude do alto peso dos ovos nos níveis mais altos, visto que a diferença no consumo foi de apenas $1 \mathrm{~g}$ de ração.

Os níveis de $\mathrm{M}+\mathrm{C}$ total da ração (Figura 3) influenciaram de forma quadrática o peso dos ovos, resultado similar aos encontrados por outros autores (Barbosa et al., 1999; Togashi et al., 2002; Sá et al., 2004; Ahmad \& Roland, 2003; Harms \& Russell, 2003). Segundo Shafer et al. (1996), a elevação do nível de ingestão de metionina de 326 para $512 \mathrm{mg} / \mathrm{ave} / \mathrm{dia}$ foi suficiente para melhorar significativamente o peso dos ovos.

Os menores pesos dos ovos nos níveis extremos de $\mathrm{M}+\mathrm{C}$ (Figura 3) podem ser explicados pelo efeito negativo da deficiência e do excesso de $\mathrm{M}+\mathrm{C}$ da ração sobre esta variável. Koelkbeck et al. (1991) classificaram a metionina como o aminoácido mais tóxico quando em excesso na ração de aves. Os menores níveis de suplementação de $\mathrm{M}+\mathrm{C}$ nas rações resultaram em ovos mais leves, o que confirma os resultados obtidos por Mendonça Jr. \& Lima (1999), em poedeiras no segundo ciclo de postura.

O valor de $0,73 \%$ de $\mathrm{M}+\mathrm{C}$ total estimado a partir do peso dos ovos representa um consumo de $794 \mathrm{mg} / \mathrm{ave} / \mathrm{dia}$,

Tabela 3 - Consumo de ração (CR), peso vivo final (PVF), ganho de peso (GP), produção de ovos (PR), peso de ovos (PO), massa de ovos (MO) e conversão por massa $(\mathrm{CMO})$ e por dúzia de ovos $(\mathrm{CDO})$, de acordo com os níveis de metionina+cistina $(\mathrm{M}+\mathrm{C})$ nas rações experimentais

Table 3 - Feed intake (FI), final body weight (FBW), weight gain (WG), egg production (EP), egg weight (EW) egg mass (EM), egg mass:feed ratio (EM/F) and egg dozen:feed ratio(ED/F) according to the dietary methionine + cystine $(M+C)$ levels

\begin{tabular}{|c|c|c|c|c|c|c|c|c|}
\hline \multirow[t]{2}{*}{$\begin{array}{l}\mathrm{M}+\mathrm{C} \text { total }(\%) \\
M+C \text { total }\end{array}$} & \multicolumn{8}{|c|}{$\begin{array}{c}\text { Característica } \\
\text { Characteristic }\end{array}$} \\
\hline & CR (g/d) & PVF (g) & GP (g) & PR (\%) & $\mathrm{PO}(\mathrm{g} / \mathrm{d})$ & $\mathrm{MO}(\mathrm{g} / \mathrm{d})$ & CMO (kg/kg) & $\mathrm{CDO}(\mathrm{kg} / \mathrm{kg})$ \\
\hline 0,61 & 109,37 & 1,744 & 112,10 & 89,50 & 59,93 & 53,64 & 2,039 & 1,473 \\
\hline 0,68 & 109,55 & 1,776 & 141,11 & 91,06 & 60,51 & 55,10 & 1,993 & 1,451 \\
\hline 0,75 & 108,74 & 1,822 & 162,13 & 87,70 & 61,25 & 53,73 & 2,036 & 1,496 \\
\hline Efeito (Effect) & $\mathrm{L} * *$ & $\mathrm{Q} * *$ & $\mathrm{~L} * *$ & $\mathrm{~L} * *$ & $\mathrm{Q} * *$ & $\mathrm{Q}^{*}$ & $\mathrm{Q}^{*}$ & $\mathrm{~L}^{*}$ \\
\hline $\mathrm{R}^{2}$ & 0,82 & 0,97 & 0,95 & 0,70 & 0,93 & 0,94 & 0,96 & 0,78 \\
\hline $\mathrm{CV}(\%)$ & 1,199 & 2,803 & 38,584 & 4,635 & 2,709 & 5,297 & 5,582 & 5,517 \\
\hline
\end{tabular}

$\mathrm{L}=$. Efeito linear (lịnear effect); $\mathrm{Q}=$ Efeito quadrático (quadratic effect); $\mathrm{ns}=$ não-significativo(not significant).

${ }^{*}(P=0,05) ;{ }^{* *}(P=0,01)$.

$\mathrm{CV}=$ coeficiente de variação (coefficient of variation) $\mathrm{R}^{2}=$ coeficiente de determinação (coefficient of determination). 
superior ao de $700 \mathrm{mg}$ de $\mathrm{M}+\mathrm{C}$ total/ave/dia estimado por Togashi et al. (2002) para poedeiras de 51 a 63 semanas de idade.

Os menores níveis de $\mathrm{M}+\mathrm{C}$ proporcionaram máxima produção de ovos (Figura 2) com baixo peso (Figura 3). À medida que o nível de $\mathrm{M}+\mathrm{C}$ total foi aumentado, o peso dos ovos também cresceu até o limite máximo de $0,73 \%$, reduzindo em seguida. A produção de ovos, por sua vez, continuou diminuindo até o máximo de $0,89 \%$, confirmando, em parte, os relatos de Harms et al. (1998), que ressaltaram a existência de uma correlação negativa entre o peso e a produção de ovos com o aumento do nível de $\mathrm{M}+\mathrm{C}$ da ração.

Foi observado efeito quadrático $(\mathrm{P} \leq 0,05)$ dos níveis de $\mathrm{M}+\mathrm{C}$ total sobre a massa de ovos, que aumentou até o nível de $0,69 \%$ (Figura 4), corroborando os resultados descritos por Togashi et al. (2002), Barbosa et al. (1999) e Sá et al. (2004).

Baião et al. (1999) e Barbosa et al. (1999) recomendaram, respectivamente, 0,65 e $0,675 \%$ de $\mathrm{M}+\mathrm{C}$ total, próximos ao valor de $0,69 \%$ estimado neste trabalho, o que reforça a recomendação de Rostagno et al. (2000), de $0,70 \%$ de $\mathrm{M}+\mathrm{C}$ total para poedeiras semipesadas. Entretanto, a estimativa foi inferior aos $0,82 \%$ apresentados por Rostagno et al. (2005).

A estimativa de $0,69 \%$ de $\mathrm{M}+\mathrm{C}$ total pela massa de ovos é correspondente ao consumo de $751 \mathrm{mg} / \mathrm{ave} / \mathrm{dia}$ e semelhante ao valor de $768 \mathrm{mg}$ para poedeiras semipesadas de 42 a 74 semanas de idade, estimado por Baião et al. (1999), e ao de $740 \mathrm{mg}$ de $\mathrm{M}+\mathrm{C}$ total/ave/dia, estimado para as aves leves por Schutte \& De Jong (1994).

O padrão de comportamento da curva de massa de ovos (Figura 4) foi semelhante ao do peso dos ovos, de modo que os níveis extremos de $\mathrm{M}+\mathrm{C}$ da ração também afetaram esta característica.

A conversão alimentar por massa de ovos apresentou efeito quadrático $(\mathrm{P} \leq 0,05)$ de acordo com os níveis de $\mathrm{M}+\mathrm{C}$

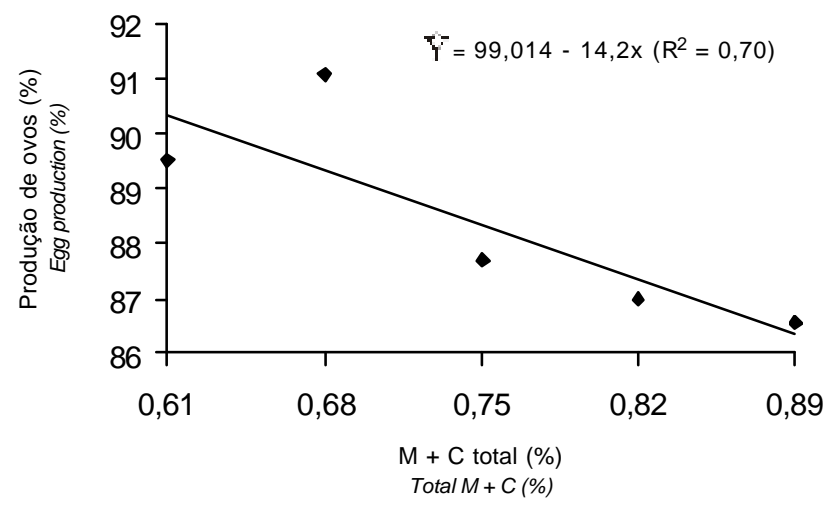

Figura 2 - Efeito dos níveis de $\mathrm{M}+\mathrm{C}$ da ração sobre a produção de ovos.

Figure 2 - Egg production according to the dietary $M+C$ total levels. da ração, com melhor resultado no nível de 0,69\% de $\mathrm{M}+\mathrm{C}$ (Figura 5). Vários autores (Barbosa et al., 1999; Mendonça Jr. \& Lima, 1999; Togashi et al., 2002; Junqueira et al., 2004; Novak et al., 2004) também encontraram efeito significativo da suplementação de $\mathrm{M}+\mathrm{C}$ sobre a conversão alimentar por massa de ovos.

O valor estimado de $\mathrm{M}+\mathrm{C}$ total pela conversão por massa de ovos de $0,69 \%$ equivale a $751 \mathrm{mg}$ de consumo/ave/dia, semelhante ao de $740 \mathrm{mg}$ estabelecido por Barbosa et al. (1999) para poedeiras durante o segundo ciclo de postura.

A conversão alimentar por dúzia de ovos piorou de forma linear $(\mathrm{P} \leq 0,05)$ com o aumento dos níveis de $\mathrm{M}+\mathrm{C}$ nas rações. Togashi et al. (2002), no entanto, trabalhando com poedeiras a partir das 51 semanas de idade, observaram efeito quadrático dos níveis de $\mathrm{M}+\mathrm{C}$ sobre a conversão por dúzia de ovos. A discrepância entre esse resultado e os deste trabalho está, provavelmente, relacionada à maior exigência de $\mathrm{M}+\mathrm{C}$ das aves no segundo ciclo de postura. Segundo Rodrigues et al. (1996), as aves, durante o segundo ciclo de postura, apresentam elevada exigência de aminoácidos

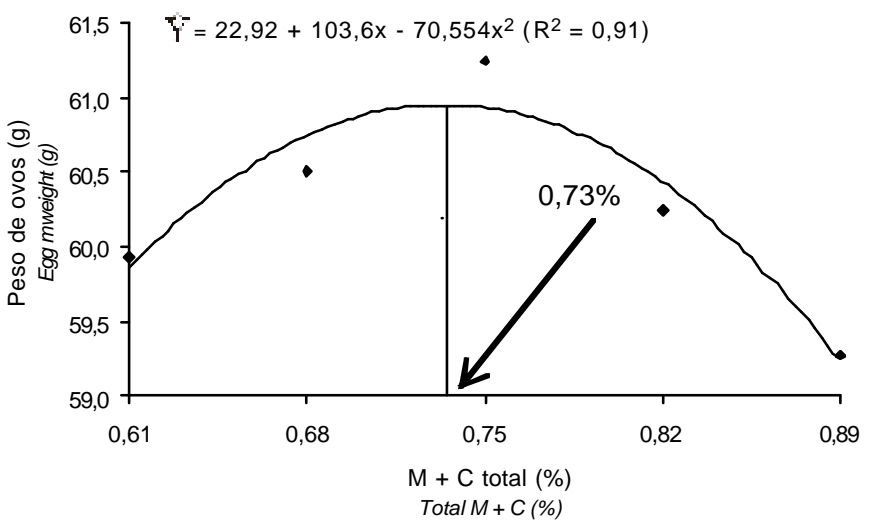

Figura 3 - Efeito dos níveis de $M+C$ total da ração sobre o peso dos ovos.

Figure 3 - Egg weight according to the dietary $M+C$ total levels.

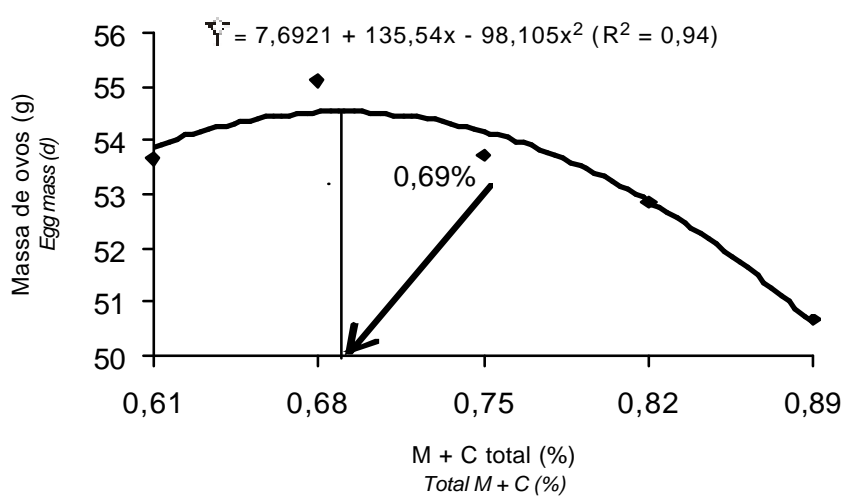

Figura 4 - Efeito dos níveis de $M+C$ total da dieta sobre a massa de ovos.

Figure 4 - Egg mass according to the dietary $M+C$ total levels. 
Tabela 4 - Consumos de metionina + cistina (CMC) e de metionina + cistina por massa de ovos (CM/MO), porcentagem de gema (PGE), clara (PCLA) e casca (PCAS), pesos de gema (PesGE), clara (PesCLA) e casca (PesCAS) e gravidade específica (GE), de acordo com os níveis de metionina+cistina $(M+C)$ na ração

Table 4 - Methionine intake (MI), egg mass per met+cys intake (EGMI), percentages of yolk (YP), albumen (AP) and shell (SP), weights of yolk (YW), albumen $(A W)$ and shell (SW) and specific gravity (SG) according to the dietary methionine + cystine $(M+C)$ levels

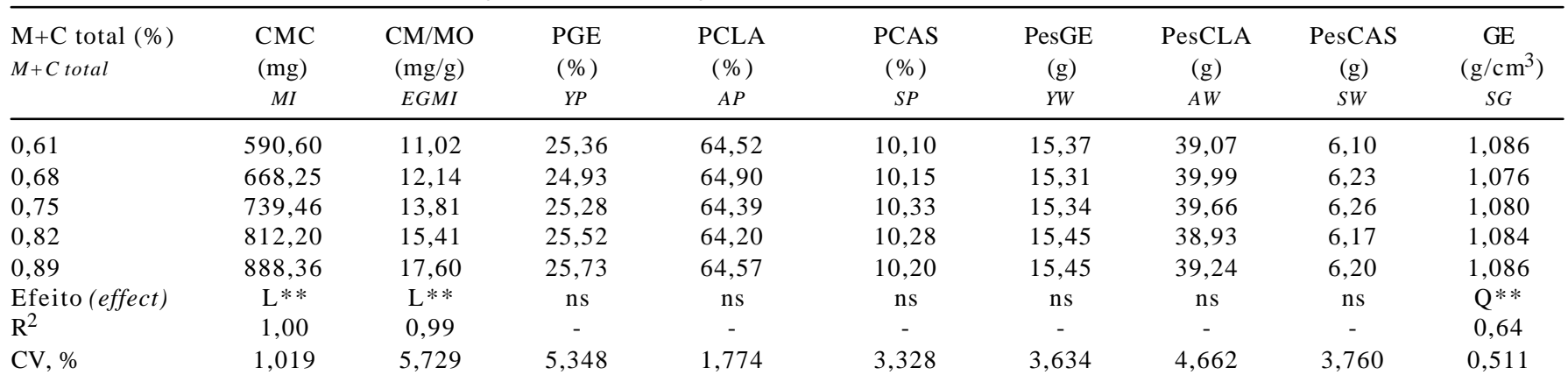

$\mathrm{L}=$ Efeito linear (linear effect); $\mathrm{Q}=$ Efeito quadrático (quadratic effect); ns = não-significativo (not significant).

${ }^{* *}(\mathrm{P}<0,01) \cdot \mathrm{CV}=$ coeficiente de variação (coefficient of variation); $\mathrm{R}^{2}=$ coeficiente de determinação coefficient of determination)

sulfurosos para a recuperação do empenamento, pois as penas são um tecido constituído quase exclusivamente de aminoácidos sulfurosos.

O consumo de $\mathrm{M}+\mathrm{C}$ total (CMC), a relação do CMC pela massa de ovos produzida, as porcentagens e os pesos de gema, clara e casca e a gravidade específica da casca dos ovos são apresentados na Tabela 4.

$\mathrm{O}$ consumo de $\mathrm{M}+\mathrm{C}$ apresentou efeito linear crescente $(P \leq 0,05)$ segundo a equação: $Y=-52,515+1056,4 X\left(R^{2}=1,00\right)$, sendo justificado pelo aumento dos níveis desses aminoácidos na ração, a exemplo dos resultados obtidos por Sá et al. (2004) e Schutte \& De Jong (1994). A conversão $\mathrm{da} \mathrm{M}+\mathrm{C}$ consumida $(\mathrm{mg})$ por unidade de massa de ovos produzida $(\mathrm{g})$ piorou linearmente $(\mathrm{P} \leq 0,05)$ à medida que $\mathrm{o}$ nível desses aminoácidos passou de 0,61 para $0,89 \%$.

Os níveis de $\mathrm{M}+\mathrm{C}$ da ração não influenciaram os pesos e as porcentagens de gema, clara e casca $(\mathrm{P} \leq 0,05)$. Rodrigues et al. (1996) e Novak et al. (2004) também relataram que o aumento dos níveis de $\mathrm{M}+\mathrm{C}$ na ração não alterou a qualidade da casca dos ovos. Por outro lado, Mendonça Jr. \& Lima (1999) encontraram influência dos níveis de M+C sobre a porcentagem e a espessura da casca. Togashi et al. (2002) também observaram efeito quadrático do aumento dos níveis de $\mathrm{M}+\mathrm{C}$ da ração sobre o peso e a porcentagem de casca. Ao contrário deste estudo, Shafer et al. (1996) constataram aumento dos pesos da gema e do albúmem com o aumento dos níveis de $\mathrm{M}+\mathrm{C}$ na ração.

A gravidade específica foi influenciada de forma quadrática $(\mathrm{P} \leq 0,01)$ conforme a equação do modelopolinomial, $Y=1,2673-0,5134 X+0,3499 X^{2}\left(R^{2}=0,63\right)$, com o pior valor obtido com $0,73 \%$ de $\mathrm{M}+\mathrm{C}$ da ração (Tabela 4 e Figura 6).

A pior gravidade específica da casca, observada com $0,73 \%$ de $\mathrm{M}+\mathrm{C}$ total, coincidiu exatamente com o mesmo valor estimado para máximo peso dos ovos (Figura 3). Este

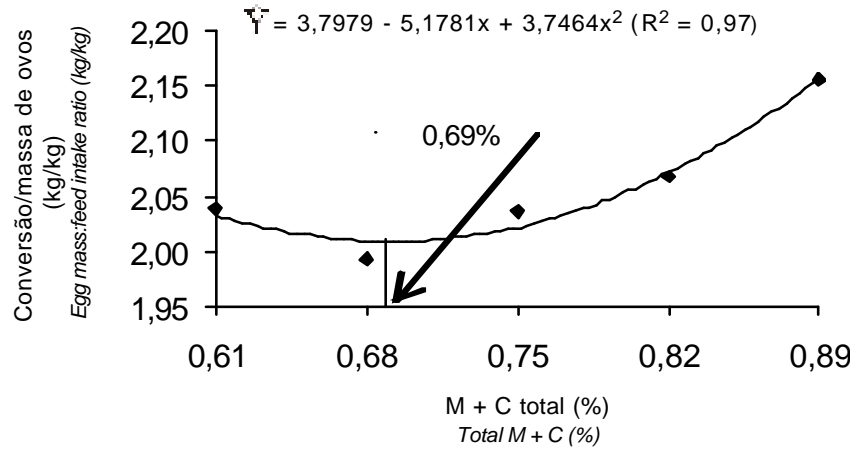

Figura 5 - Efeito dos níveis de $M+C$ da ração sobre a conversão alimentar por massa de ovos.

Figure 5 - Egg mass:feed intake ratio according to the dietary $M+C$ total levels.

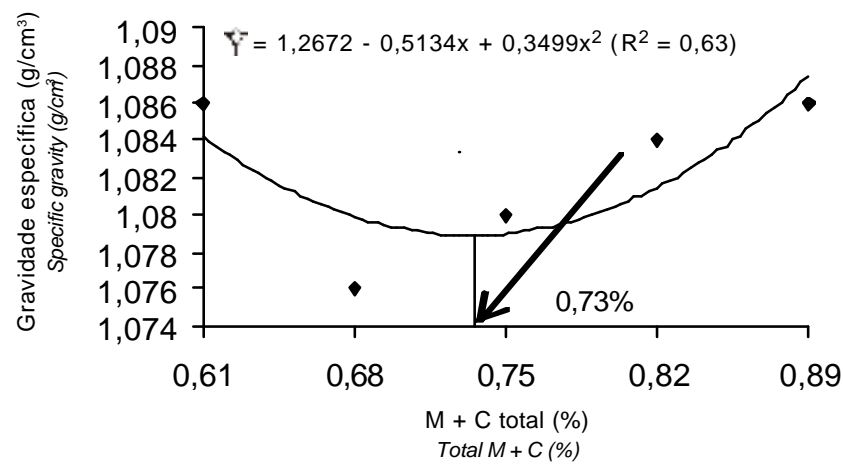

Figura 6 - Efeito dos níveis de $M+C$ sobre a gravidade específica.

Figure 6 - Especific gravity according to the dietary $M+C$ total levels.

resultado parece corroborar os dados de Roland (1986), que demonstrou redução na proporção de casca de 9,92 para $8,41 \%$ quando o peso do ovo passou de 50 para $64 \mathrm{~g}$. Mendonça Jr. \& Lima (1999), trabalhando com poedeiras, observaram máximo peso dos ovos de $63,8 \mathrm{~g}$ e gravidade específica mínima de $1,0842 \mathrm{~g} / \mathrm{cm}^{3}$ no nível de $0,635 \%$ de $\mathrm{M}+\mathrm{C}$ na ração. 
O nível médio de $0,70 \%$ de $\mathrm{M}+\mathrm{C}$ total encontrado neste trabalho a partir das estimativas do peso $(0,73 \%)$, da massa $(0,69 \%)$ e da conversão alimentar por massa de ovos $(0,69 \%)$ confirma a recomendação de Rostagno et al. (2000), de $0,70 \%$. A porcentagem de $0,70 \%$ de $\mathrm{M}+\mathrm{C}$ total equivale a $0,64 \%$ de $\mathrm{M}+\mathrm{C}$ digestível ou ingestão de 762 e $697 \mathrm{mg}$ de $\mathrm{M}+\mathrm{C}$ total e digestível, respectivamente. Esse consumo de $762 \mathrm{mg}$ totais é similar aos $761 \mathrm{mg}$ encontrado por Barbosa et al. (1999) em poedeiras semipesadas.

\section{Conclusões}

A exigência de metionina + cistina total e digestível para poedeiras semipesadas do início de postura até o final do pico de produção foi estimada, respectivamente, em $0,70 \mathrm{e}$ $0,64 \%$ ou consumo de 762 e $697 \mathrm{mg} / \mathrm{ave} / \mathrm{dia}$.

\section{Literatura Citada}

AHMAD, H.A.; ROLAND, D.A. Effect of environmental temperature and total sulfur amino acids on performance and profitability of laying hens: an econometric approach. Journal of Applied Poultry Research, v.12, n.4, p.476-482, 2003.

BAIÃO, N.C.; FERREIRA, M.O.O.; BORGES, F.M.O. et al. Efeito dos níveis de metionina da dieta sobre o desempenho de poedeiras comerciais. Arquivo Brasileiro de Medicina Veterinária e Zootecnia, v.51, n.3, p.271-274, 1999.

BAKER, D.H.; FERNANDEZ, S.R.; WEBEL, D.M. et al. Sulfur amino acid requirement and cystine replacement value of broiler chicks during the period three to six weeks post-hatching. Poultry Science, v.75, n.6, p.7337-7342, 1996.

BARBOSA, B.A.C.; SOARES, P.R.; ROSTAGNO, H.S. et al. Exigência nutricional de metionina+cistina para galinhas poedeiras de ovos brancos e marrons, no segundo ciclo de produção. 1. Características produtivas. Revista Brasileira de Zootecnia, v.28, n.3. p.526-533, 1999.

CALDERON, V.M.; JENSEN, L.O. The requirement for sulfur amino acid by laying hens as influenced by the protein concentration. Poultry Science, v.69, p.934-944, 1990.

GIETZEN, D.W. Neural mechanisms in the response to amino acid deficiency. Journal of Nutrition, v.123, p.610-625, 1993.

GOULART, C.C. Exigências nutricionais de lisina para poedeiras leves e semipesadas. Viçosa, MG: Universidade Federal de Viçosa, 1997. 52p. Dissertação (Mestrado em Zootecnia) - Universidade Federal de Viçosa, 1997.

HARMS, R.H.; RUSSELL, G.B. Performance of commercial laying hens fed diets with various levels of methionine. Journal of Applied Poultry Research, v.12, n.4, p.449-455, 2003.

HARMS, R.H.; RUSSEL, G.B.; HERLOW, H. et al. The influence of methionine on commercial laying hens. Journal of Applied Poultry Reseach, v.7, p.45-52, 1998.

HEMPE, J.M.; LAUXEN, R.C.; FAGAGE, J.E. A rapid determination of egg weight and specific gavity using computerized collection system. Poultry Science, v.67, p.902-907, 1988.

JUNQUEIRA, O.M.; FILARDI, R.S.; LAURENTIZA, A.C. et al. Efeito dos níveis de metionina + cistina em rações de pósmuda e de produção sobre o desempenho de poedeiras no segundo ciclo de postura. In.: REUNIÃO ANUAL DA SOCIEDADE BRASILEIRA DE ZOOTECNIA, 2004, Campo Grande. Anais... Campo Grande: Sociedade Brasileira de Zootecnia, 2004 (CD-ROM).

KOELKEBECK, K.W.; BAKER, D.H.; HAN, Y. et al. Research note: effect of excess lysine, methionine, threonine, or tryptophan on production performance of laying hens. Poultry Science, v.70, p.1651-1653, 1991.

LEUNG, P.M.B.; ROGERS, Q.R. Importance of prepyriform cortex in food intake response of rats to amino acids. American Journal of Physiology, v.221, p.929-935, 1971.

MACARI, M.; FURLAN, R.L.; GONZALES, E. Fisiologia aviária aplicada a frangos de corte. Jaboticabal: FUNEP/UNESP, 1994. 296p.

MENDONÇA JR., C.X.; LIMA, F.R. Efeito dos níveis de proteína e de metionina da dieta sobre o desempenho de galinhas poedeiras após a muda forçada. Journal Veterinary Research and Animal Science, v.36, p.332-338, 1999.

NATIONAL RESEARCH COUNCIL - NRC. Nutrient requeriments of poultry. 9.ed. Washington, D.C.: National Academic Press, 1994. $155 \mathrm{p}$.

NOVAK, C.L.; YAKOUT, H.S.; SCHEIDELER, S. The combined effects of dietary lysine and total sulfur amino acid level on eggs production parameters and egg components in dekalb delta laying hens. Poultry Science, v.83, p.977-984, 2004.

PARK, B,C.; AUSTIC, R.E. Changes in hepatic branched-chain áketo acid dehydrogenase activity in response to isoleucine imbalance in growing chickens. Journal of nutrition of Biochemistry, v.9, p.687-696, 1998.

RODRIGUES, P.B.; BERTECHINI, A.G.; OLIVEIRA, B.L. Fatores nutricionais que influenciam a qualidade do ovo no segundo ciclo de produção. I. Níveis de aminoácidos sulfurosos totais. Revista Brasileira de Zootecnia, v.25, n.2, p.248-260, 1996.

ROLAND, D.A. Egg shell quality. III: calcium and phosphorus requeriments of commercial leghorns. World's Poultry Science Journal, v.42, p.154-165, 1986.

ROSTAGNO, H.S.; ALBINO, L.F.T.; DONZELE, J.L. et al. Tabelas brasileiras para aves e suínos: composição de alimentos e exigências nutricionais. 2.ed. Viçosa, MG: Universidade Federal de Viçosa, 2005. 186p.

ROSTAGNO, H.S.; ALBINO, L.F.T.; DONZELE, J.L. et al. Tabelas brasileiras para aves e suínos: composição de alimentos e exigências nutricionais. Viçosa, MG: Universidade Federal de Viçosa, 2000. 141p.

SÁ, L.M.; GOMES, P.C.; ROSTAGNO, H.S. et al. Exigência de metionina + cistina para poedeiras leves no período de 34 a 50 semanas de idade. In.: REUNIÃO ANUAL DA SOCIEDADE BRASILEIRA DE ZOOTECNIA, 2004, Campo Grande. Anais... Campo Grande: Sociedade Brasileira de Zootecnia, 2004. CD-ROM.

SCHUTTE, J.B.; DE JONG, J. Requirement of the laying hen for sulfur amino acids. Poultry Science, v.73, p.274-280, 1994.

SHAFER, D.J.; CAREY, J.B.; PROCHASKA, J.F. Effect of dietary methionine intake on egg component yield and composition. Poultry Science, v.75, p.1080-1085, 1996

SIDRAUSKEJ, H.; BABA, T. Chemical pathology of acute amino acid deficiencies. III. Morphology and biochemical changes in young rats fed valine or lysine devoid diets. Journal of Nutrition, v.70, p.463-483, 1960 .

SILVA, J.H.V.; JORDÃO FILHO, J.; SILVA, E.L. Por que formular rações para poedeiras com base no conceito de proteína ideal? Revista Ave World, v.3, n.3, p.50-57, 2005.

SILVA, J.H.V.; MUKAMI, F.; ALBINO, L.F.T. Uso de rações à base de aminoácidos digestíveis para poedeiras. Revista Brasileira de Zootecnia, v.29, n.5, p.1446-1451, 2000.

TOGASHI, C.K.; FONSECA, J.B.; SOARES, R.T.R.N. et al. Determinação de níveis de metionina + cistina para poedeiras semipesadas alimentadas com rações contendo levedura seca. Revista Brasileira de Zootecnia, v.31, n.3, p.1426-433, 2002 (supl.).

UNIVERSIDADE FEDERAL DE VIÇOSA - UFV. SAEG - Sistema para Análise Estatística e Genética. Versão 5.0. Viçosa, MG: Fundação Artur Bernardes, 1993.

Recebido: 21/12/04 Aprovado:02/12/05 